\title{
Gamers and Video Games Users: What's the Difference?
}

The term "gamer" is commonly used to refer to individuals who play video games frequently. However, building on Self- Determination theory (SDT) and the Dualistic Model of Passion (DMP), we argue that it may be more theoretically and practically useful to operationalize individuals as "gamers" versus "non- gamers" based on their identification and passion for gaming rather than based on how frequently individuals play video games. Thus, the purpose of the present study is to compare four groups, those who identify as gamers or non-gamers with those who have frequent use or not, on independent variables of gaming engagement, motivation, and problematic gaming. Participants $\left(N=1,050 ; 70.10 \%\right.$ men; $M_{\text {age }}=23.74$ years, $S D=6.48$ years $)$ completed measures online. Results revealed that identifying as a gamer was a stronger predictor of levels of gaming engagement, motivation, and problematic gaming compared to frequent use. Findings highlight the potential of SDT and DMP for understanding gamer characteristics.

The term gamer elicits in most a stereotyped idea of an adolescent male who plays video games excessively (i.e., 20+ hours of gaming per week). But who really is a gamer, and more specifically, how does a gamer differ from a video game user? There is an important increase in popularity of video gaming and heightened discourse surrounding problematic gaming. Therefore, the operationalization of gamers as having a strongly endorsed social identity, the process by which research classifies these individuals as gamers, and the factors that differentiate them from a video game user are methodologically important to establish. Vallerand $(2010,2015)$ suggests that individuals who engage passionately with an activity will present a different pattern of engagement 
and motivation toward the activity than those who do not socially identify with the activity. Furthermore, greater passion toward gaming may elicit a stronger endorsement of an unhealthy or problematic style of gaming engagement compared to playing video games frequently. The purpose of the present study is to compare gamers (defined by their level of passion toward video games) and video game users (defined as individuals reporting a frequent use of video games) across indices of gaming engagement, gaming motivation, and problematic gaming.

The first section of this paper reviews the current literature surrounding previous measures used to operationalize video game playing, which focus largely on differing measures of time spent playing and pinpoints problems associated with this method. Then, the importance of social identification toward gaming is addressed, followed by a discussion of the criteria for Internet gaming disorder. The literature review concludes with a section on Self- Determination Theory as this theoretical framework represents the pillar for the present study's differentiation between a gamer and a video game user.

\section{Previous Definitions of Gamers}

In deciding how to define gamers, previous researchers have used different measures of gaming to classify gamers. These primarily include a measurement of time spent playing (e.g., Winn \& Heeter, 2009) and social identification toward gaming (e.g., Neys, Jansz, \& Tan, 2014); however, endorsement of problematic gaming symptomatology may also contribute to the definition of gamer (e.g., spending a lot of time thinking about games even when not playing). Researchers have generally relied on one measurement approach, although there are some studies that have used more than one 
method (e.g., Kowert \& Oldmeadow, 2015). As discussed below, each of these methodologies have some inherent difficulties.

The use of time spent playing can be assessed in different ways. For instance, Winn and Heeter (2009) focused on the relationship between available free time and the quantity of video game use. They found that college students with less leisure time spend less time playing video games. An issue with using time spent gaming is that individuals may still socially identify with an activity even though they do not have as much free time to engage in video games as they would prefer. Moreover, Williams and colleagues (2009) found self-reported estimates of time spent gaming to be incorrect when compared to hours that had been logged by the computer. Taken together, two issues arise from using a measure of time spent gaming in defining gamers. First, it is problematic to assume that the definition of a gamer requires large quantities of use due to varying levels of free time across individuals. Second, estimates of time spent gaming have been shown to be inaccurate at times.

A measure of social identification toward gaming has also been used in recent research. Neys and colleagues (2014) asked participants to classify themselves as hard core, heavy, or casual gamers. Although their findings provided some validity showing that hard core gamers reported more time spent gaming than heavy or casual gamers, based on the results from Williams, Consalvo, Caplan, and Yee (2009) these differences may not be accurate. Moreover, as Shaw (2012) points out, females are less likely to classify themselves as gamers if asked, resulting in the possible exclusion of females from the gamer category when this methodology is employed. Another method of acquiring a level of participants' social identification toward gaming, which extends 
beyond a single item question, resides in applying the Dualistic Model of Passion. For example, if an individual indicates a passion for gaming they are indicating that gaming is integral to their sense of self (Vallerand, 2010, 2015). Currently, this more complex method of distinguishing gamers from frequent but non-socially identified gamers has not been utilized.

Finally, although studies of problematic gaming are common, few examine the relationship between problematic gaming and social identification toward gaming. Recently, the American Psychiatric Association (APA) has recognized problematic gaming in the Diagnostic and Statistical Manual for Mental Disorders (DSM; APA, 2013) as an emerging construct. It is broadly defined as the inability to adequately meet day-to-day responsibilities due to video game use (although frequency per se is not the sole determinant; Brunborg, Mentzoni, \& Froyland, 2014; King, Haagsma, Delfabbro, Gradisar, \& Griffiths, 2013; Lemmens, Valkenburg, \& Peter, 2011; Wei, Chen, Huang, \& Bai, 2012). Specifically, Internet gaming disorder, as it is referred to in the DSM, is based on a set of nine criteria, such as experiencing withdrawal symptoms when one is unable to play video games, a loss of interest in hobbies or activities that are not video gaming as well as playing video games to stop experiencing negative moods (APA, 2013).

Essentially, problematic gaming can be described as the detrimental impact of gaming on a person's well-being in various aspects of their life. Several scholars have suggested that problematic behaviours, such as problematic gaming, differ in large part from substance addictions in that the activity is so strongly integrated to the self, implying a positive correlation between gamer identification and gaming disorder (King 
et al., 2013; Lafreniere, Vallerand, Donahue, \& Lavigne, 2009). Moreover, Charlton (Charlton, 2002; Charlton, \& Danforth, 2007) suggests that several symptoms of problematic gaming, referred to as peripheral criteria, can be associated with high engagement rather than with a disorder. In other words, people engaging problematically in video games differs from people with a substance addiction because they socially identify with video games, suggesting that their sense of self is inextricably linked with the activity, whereas the people with a substance addiction are motivated by the euphoric experience of the drug.

Therefore, endorsing one or two symptoms of gaming disorder that correspond to Charlton's peripheral criteria could possibly suggest enthusiastic engagement without necessarily engaging in problematic gaming. Following this logic, reporting zero symptoms might imply a complete lack of engagement towards gaming. On the other hand, similar to self-reports of time spent and social identification toward gaming, males generally report a greater quantity of problematic gaming symptoms than females, implying an inherent gender bias (Lemmens, Valkenburg, \& Gentile, 2015; Muller et al., 2015; Rehbein, Kliem, Baier, Möble, \& Petry, 2015).

To summarize, research in the area of gaming has tended to use a definition of socially identified gamers that at times is arbitrary and may even be biased toward male gamers. Thus, it may be helpful to refer to theory to establish a new operationalization of a social identification toward gaming. Self- Determination Theory (SDT; Deci \& Ryan, 1985; Ryan \& Deci, 2000), as described in the following section, provides a framework from which to study activity engagement, and may serve well in establishing key elements within the gamer definition. 


\section{Self-Determination Theory and Gaming}

SDT is a theory of human motivation that broadly supposes humans to be inherently motivated to engage in activities in environments that support the satisfaction of basic psychological needs (competence, autonomy, and relatedness; Ryan \& Deci, 2000). Previous research has shown that individuals may, in fact, experience needs satisfaction while gaming (e.g., Ryan, Rigby, \& Przybylski, 2006; Tamborini, Bowman, Eden, Grizzard, \& Organ, 2010). Founded on SDT, Vallerand (2010, 2015), in his Dualistic Model of Passion (DMP), proposes passion to be a psychological construct defined as a meaningful, self- defining activity. Individuals are assumed to be strongly motivated to engage in their passions due to deriving a sense of self-engagement as well as through the satisfaction of competence, autonomy, and relatedness needs (Mageau et al., 2009; Vallerand, 2010, 2015; Vallerand et al., 2003).

Although previous research has successfully applied DMP to video game engagement, research has not assessed differences between passionate and nonpassionate gamers (Lafrenière, Vallerand, Donahue, \& Lavigne, 2009; Przybylski, Weinstein, Ryan, \& Rigby, 2009; Utz, Jonas, \& Tonkens, 2012). Due in part to the sense of self that is derived from gaming engagement, differences between passionate and nonpassionate gamers are expected, as a passionate gamer is one that has a strong social identity as a gamer. The pattern of video game engagement, for instance, is expected to differ between passionate and non- passionate gamers, with passionate gamers reporting greater gaming engagement compared to non- passionate gamers. Further differences may include reports of problematic gaming symptomology and gamers' overall motivations for engaging in video games, with passionate gamers reporting greater 
problematic gaming and stronger motivation toward gaming relative to non-passionate gamers.

Importantly, differences in reports of gaming motivation between gamers and non-gamers are expected, given the assumed intrinsic draw toward gaming experienced by gamers, although this has yet to be directly examined. Indeed, motivation toward gaming have been studied using different frames of reference. Yee (2006) and Fuster and colleagues (2012), for example, explored gaming motivation from a use and gratification perspective, suggesting gamers are motivated to play to socialize, compete, escape, and explore through gaming. Alternatively, King, Delfabbro, and Griffiths (2009) explored gaming motivation as it relates to specific characteristics of video games, such as humor within the game, control options, or multiplayer features. Both perspectives have added insight into gaming motivations, but they do not investigate beyond individual gamers or specific video games. SDT, on the other hand, provides a framework from which to understand gaming motivation as it relates to the extent gaming engagement is regulated by the self in a way that is not limited to specific gamers or video games (Deci \& Ryan, 2000; Ryan, 1995).

According to SDT, motivation exists upon a continuum of self-regulation of activity engagement (Deci \& Ryan, 2000; Ryan, 1995). Engagement in an activity that is intrinsically motivated reflects engagement for the sake of the activity itself without consideration of possible rewards. An extrinsic motivation reflects engagement in an activity for reasons beyond the activity itself (e.g., rewards, punishment). Unlike intrinsic motivation, extrinsic motivation vary in activity engagement, resulting in four subtypes of extrinsic motivation: external regulation, introjected regulation, identified 
regulation, and integrated regulation. External regulation is the prototypic case of extrinsic motivation where engagement is directly related to the possibility of earning rewards or avoiding punishments from an authority figure. Introjected regulation consists of uncontrollable internal pressures such as guilt or anxiety to engage in the activity. Identified regulation implies that engagement in the activity is related to reasons that do not relate directly to the activity itself but that are perceived as important to the individual. Finally, an integrated regulation reflects engagement in an activity representing an extension of self. Beyond both intrinsic and extrinsic motivations is amotivation toward activity engagement. This form of regulation suggests the individual is disinterested in their engagement as well as unable to pinpoint why they are engaging in the activity at all (Deci \& Ryan, 2000; Ryan, 1995).

Previous research has successfully applied SDT to video game engagement in several recent studies(Beard \& Wickham, 2016; Johnson, Gardner, \& Sweetser, 2016; Przybylski, Rigby, \& Ryan, 2010). Lafrenière and colleagues (2012) developed The Gaming Motivation Scale (GAMS) to assess each of the six motivation types for gaming engagement in SDT. In validating their items, gaming hours per week was weakly correlated with all motivations except amotivation. In another study by Neys and colleagues (2014), an adapted version of The Situational Motivation Scale was used to assess gaming motivation differences between individuals who classified themselves among casual, heavy, or hardcore gamers (i.e., select which best describes your level of gaming engagement). Individuals socially identifying as hardcore gamers reported stronger intrinsic and extrinsic motivations than casual and heavy video game users, but weaker amotivation. Although this study provides some indication that motivation varies 
across social gaming identities, further research is needed with a more comprehensive measure of social identification toward gaming.

Thus, the overarching objective of the present study is to compare four groups: those who socially identify as gamers or non-gamers (i.e., do or do not report a passion for gaming; $\mathrm{G}, \mathrm{NG}$ ) with those who have frequent use or not (i.e., game most days of week or not; FU, NFU) on variables of gaming engagement, motivation, and problematic gaming. However, prior to addressing this objective, gender differences were assessed for gaming engagement, motivation, and problematic gaming, in order to determine whether gender should be considered as a covariate.

\section{Hypotheses}

Combining Vallerand's $(2010,2015)$ work on passion and identity as well as Neys and colleagues' (2014) research on identity and frequency of play, it was hypothesized that self-identified gamers will report greater gaming engagement (H1a), problematic gaming $(\mathrm{H} 2 \mathrm{a})$, and motivation toward gaming $(\mathrm{H} 3 \mathrm{a})$ than non-gamers. It is also expected that users who report engaging in video games most days of the week will report more hours per week gaming and greater frequency of gaming during their free time than those not engaging in video games most days of the week. It is also hypothesized that frequent users will report greater gaming engagement $(\mathrm{H} 1 \mathrm{~b})$, problematic gaming $(\mathrm{H} 2 \mathrm{~b})$, and motivation toward gaming $(\mathrm{H} 3 \mathrm{~b})$ than non-frequent users. However, the greatest gaming engagement is expected for individuals who report a frequent use of video games as well as a strong social identification toward gaming. As a result, individuals classified as both a gamer and a frequent user will report the greatest 
level of gaming engagement $(\mathrm{H} 1 \mathrm{c})$, problematic gaming $(\mathrm{H} 2 \mathrm{c})$, and motivation toward gaming $(\mathrm{H} 3 \mathrm{c})$.

\section{Method}

\section{Participants}

Participants $\left(N=1,352 ; 70.10 \%\right.$ males; $M_{\text {age }}=23.74$ years, $S D=6.48$ years $)$ were recruited via email invitations and advertisements on social media websites (e.g., Reddit, Facebook) and a large university campus. The ad specified that this study would examine video game motivation with video games including casual games played through online gaming and social media websites as well as on cell phones and other devices. Out of this sample, $302(22.30 \%)$ submitted online questionnaires with missing values that could not be imputed and were therefore excluded, resulting in a final sample of 1,050 participants ( $69.60 \%$ males; $M_{\text {age }}=23.88$ years, $S D=6.32$ years).

\section{Measures}

Demographics. At the beginning of the Video Game Use measure, participants were asked for their age, gender, and whether they play video games most days of the week or not.

Gaming frequency. A series of items assessed participants' video game use. Participants provided

(1) an estimation of their average gaming hours per week, which was used as a dichotomous categorizing variable (whether participants gamed most days of the week or not), for frequent and non-frequent groups, and (2) reported the frequency with which 
they play video games in their free time on a 5-point scale ranging from 1 (Never) to 5 (Always). Another two items addressed the frequency with which participants use video games to manage their stress ("How frequently do you use video games to cope with stress?") as well as the quantity of their video game use perceived to manage their stress ("How frequently do you use video games to cope with stress?"). The last two items were rated on 4-point scales ranging from Never to Always for frequency, and from None, I don't find video game use helps me cope to Almost whenever I play video games for quantity use. The last two items were found to be highly correlated $(r=.71)$; therefore, the average between the two items was used as an overall measure of individuals' use of video games to manage stress.

Gaming Motivation Scale. Lafrenière and colleagues (2009) developed the 18item Gaming Motivation Scale (GAMS) to assess levels of motivation toward gaming across the six identified motivation types (intrinsic, integrated, identified, introjected, and external). Items were rated on a 7- point Likert scale ranging from 1 (Not at all agree) to 7 (Very strongly agree). Each motivation type was assessed with three items. The internal consistency of the six subscales ranged from $\alpha=.62$ to $\alpha=.86$.

Internet Gaming Disorder Scale. This scale consists of nine items developed by Lemmens and colleagues (2015). Each item corresponds to one of the proposed criteria for Internet gaming disorder and to the extent it was experienced during the last year (e.g., "During the last year, how often have there been periods when all you could think of was the moment that you could play a game?"). Participants were asked to rate each item on an adapted 6-point scale ranging from 1 (Almost never) to 6 (Almost always). The 
internal consistency of the Internet Gaming Disorder Scale for the present sample was $\alpha$ $=.85$.

Passion. Four items from Vallerand's (2010) Passion Scale were used to assess the extent to which participants reported video game engagement to be a meaningful, self-defining activity (e.g., "This activity is very important to me"). Each item was rated on a 7- point Likert scale ranging from 1 (Not at all agree) to 7 (Very strongly agree). The internal consistency of these four items for the present sample was $\alpha=.89$. Average scores equal to or greater than four were classified as gamers, whereas average scores less than four were classified as non-gamers based on Mageau and colleagues' classifications of passion (2009).

\section{Results}

Seventy-seven participants (7.30\%) were detected as either univariate outliers (-/+ $3 \mathrm{SDs}$ ) on one or more measures or a multivariate outlier across all measures, and therefore excluded from further analyses. The final sample consisted of 973 participants $\left(69.90 \%\right.$ male; $M_{\text {age }}=23.32$ years, $\left.S D=4.70\right)$ including 843 frequent video game users $(86.60 \%)$ and 670 gamers $(68.90 \%)$. Not surprisingly, a large majority of frequent video game users $(76 \%)$ were also classified as gamers. Finally, no violations of normality were observed with skew statistics ranging from -0.81 to 1.55 (George \& Mallery, 2010). All analyses were performed on SPSS version 22 with Type III sums of squares to account for expected imbalance in the cell sizes (Lewsey, Gardiner, \& Gettinby, 1997).

\section{Preliminary Analyses}


Prior to conducting the primary analyses, gender differences were explored to determine if gender should be included as a covariate in the planned analyses. Table 1 presents the averages for gaming engagement, gaming motivation, and problematic gaming. As evidenced, significant gender differences were observed across all variables of interest except for reports of amotivation toward gaming. Furthermore, as shown in Table 2, gender was found to be significantly associated with membership to both groups such that more males were classified as passionate gamers and frequent users than females. These findings suggest gender indeed may influence the results of the objective of the study and should therefore be included as a covariate.

\section{Primary Analyses}

A 2 × 2 (gamer, non-gamer * frequent user, non- frequent user) MANCOVA was conducted for gaming engagement (i.e., hours gaming per week, frequency playing in free time, and frequency of gaming to manage stress) with gender entered as a covariate. Prior to conducting the MANCOVA, the correlations of the dependent variables were assessed to determine any issues with multicollinearity. Significant associations were found between frequency playing in free time and hours per week gaming, $r(971)=.62$, $p<.001$, frequency playing in free time and frequency of gaming to manage stress, $r(971)=.33, p<.001$, and hours per week gaming and frequency of gaming to manage stress, $r(971)=.44, p<.001$. The correlations do not suggest issues with multicollinearity resulting in the MANCOVA being conducted as planned. Note that Box's M test suggested the assumption of equal variances had been violated $(p<.001)$. Results revealed significant main effects for the gamer/non- gamer classification, Wilk's $\lambda=.85, F(3,966)=57.00, p<.001$, partial $\eta^{2}=.15$, and frequent $/$ non- frequent user 
classification, Wilk's $\lambda=.84, F(3,966)=52.28, p<.001$, partial $\eta^{2}=.16$, as well as a significant interaction effect, Wilk's $\lambda=.97, F(3,966)=9.96, p<.001$, partial $\eta^{2}=.03$. The results from follow-up univariate analyses are shown in Table 3 (gamer, non-gamer) and in Table 4 (frequent user, non -frequent user). Greater gaming engagement was reported by gamers and frequent users relative to non- gamers and non-frequent users, respectively, thus supporting the hypothesis that gamers will report greater gaming engagement than non-gamers (H1a) and that frequent users will report greater gaming engagement than non-frequent users (H1b). Finally, univariate analyses revealed the interaction between the social identification toward gaming and frequent user groups to be significant for hours gaming per week $F(3,968)=13.51, p<.001$, partial $\eta^{2}=.01$, and frequency of use during free time, $F(3,968)=4.43, p=.04$, partial $\eta^{2}=.01$, partially supporting the hypothesis that individuals identifying both as gamers and frequent users will report the greatest level of gaming engagement $(\mathrm{H} 1 \mathrm{c})$. As shown in Figure 1, participants classified as both a socially identified gamer and frequent user reported the most hours gaming per week as well as the most frequent use of gaming in free time. The interaction for the frequency of gaming to manage stress was not significant, $F(3,968)=1.41, p=.24$.

Additionally, a 2 x 2 (gamer, non-gamer * frequent user, non-frequent user) ANCOVA was conducted for reports of problematic gaming, with gender entered as a covariate. As with the previous analysis, results from Levene's test suggested the assumption of equal variances had been violated $(p<.001)$. The interaction effect was found to be non-significant, $F(1,968)=0.20, p=.65$, not supporting the hypothesis that suggests identifying as a gamer and a frequent user will lead to greater reports of 
problematic gaming $(\mathrm{H} 2 \mathrm{c})$. Thus, prior to reviewing the main effects, theANCOVA was conducted again as a main effects model. Results revealed significant main effects for both the gamer classification, $F(1,968)=93.65, p<.001$, partial $\eta^{2}=.09$, and frequent user classification, $F(1,968)=18.92, p<.001$, partial $\eta^{2}=.02$. The averages are reported in Tables 3 and 4, which supported the hypothesis that suggests that gamers will report greater levels of problematic gaming than non-gamers $(\mathrm{H} 2 \mathrm{a})$ and that frequent users will report greater levels of problematic gaming than non-frequent users $(\mathrm{H} 2 \mathrm{~b})$.

Finally, a 2 × 2 (gamer, non-gamer * frequent user, non-frequent user) MANCOVA was conducted for gaming motivations, with gender entered as a covariate. Once again, Box's M test suggested that the assumption of equal variances had been violated $(p<.001)$. Due to the interaction effect not being significant, Wilk's $\lambda=.99$, $F(6,963)=1.93, p=.07$, thus not supporting $\mathrm{H} 3 \mathrm{~b}$. This suggested that individuals identifying as both gamers and frequent users will report the greatest levels of motivation towards gaming, the MANCOVA was conducted again as a main effects model. Results revealed significant main effects for both the gamer classification, Wilk's $\lambda=.68, F(6$, 964) $=76.3, p<.001$, partial $\eta^{2}=.32$, and frequent user classification, Wilk's $\lambda=$ $.97, F(6,964)=4.96, p<.001$, partial $\eta^{2}=.03$. The results from the follow- up univariate analyses revealed that, compared to non-gamers, gamers reported a strong motivation overall to engage in video games (see Table 3). Similarly, compared to nonfrequent users, frequent users reported a stronger motivation to engage in video games (see Table 4). These results largely support the hypotheses that stated that gamers will report greater motivation toward gaming than non-gamers $(\mathrm{H} 3 \mathrm{a})$ and that frequent users will report greater motivation towards gaming than non-frequent users $(\mathrm{H} 3 \mathrm{~b})$. 


\section{Discussion}

The present paper sought to examine the differences between gamers and video game users on gaming engagement (i.e., time spent playing per week, frequency of gaming in free time, and frequency of gaming to manage stress), the level of problematic gaming, and the motivation towards gaming. This is the first study to apply reports of passion toward gaming as a method of classifying gamers, highlighting the methodological importance of considering an individual's identification with gaming beyond reports of frequency of gaming. The following section discusses the findings in the context of previous studies and interprets the potential impact these findings have on theory and methodological considerations for future gaming research.

Although not a primary objective, the first step in the analyses was to investigate possible gender differences across variables to consider if gender should be controlled for in the main analyses. A pattern consistent with previous literature was found, whereby males reported greater gaming engagement and problematic gaming compared to females (Lucas \& Sherry, 2004; Muller et al., 2015; Padilla-Walker, Nelson, Carroll, \& Jensen, 2010; Winn \& Heeter, 2009). Furthermore, compared to females, males were found to report higher levels of all types of motivation toward gaming except for amotivation and were more likely to identify socially as a gamer. It is possible that the differences in motivation toward gaming between males and females is explained by the overt sexism and misogyny observed in the gaming culture, which might decrease females' motivation for and social identification toward gaming (e.g., Fox \& Tang, 2014; McClean \& Griffiths, 2013). In other words, despite using reports of passion for classifying gamers and non-gamers, this study was still unable to counter the effects of gender stereotypes 
and sexism in gaming on females' identification as gamers. Therefore, future research may benefit to build on the results from Fox and Tang (2014) in addressing the extent to which the experience of sexism during gaming deters female gamers from identifying with, developing a passion for, and reporting a strong motivation for gaming.

As noted above, the primary goal of the present paper was to compare reports of gaming engagement, level of problematic gaming, and gaming motivation across two dichotomous classifications representing socially identified gamers versus non-gamers and frequent versus non-frequent users. Given the gender differences that were observed, gender was included as a covariate. The findings largely supported the hypotheses. First, although not surprisingly, gamers and frequent video game users reported greater gaming engagement and problematic gaming than non-gamers and non-frequent video game users, respectively. Furthermore, in line with expectations, being classified as both a socially identified gamer and a frequent video game user was associated with the highest level of gaming engagement, specifically greater time spent playing and frequency of gaming in free time, but not frequency using gaming to cope.

Importantly, some individuals still reported being passionate towards gaming despite being non-frequent video game users. Therefore, by focusing only on time spent playing in the classification of gamers, as it has been done in previous literature, research may miss those passionate gamers who do not frequently play video games. Although they are only a small percentage, including the non-frequent gamer category still provides a deeper understanding of these categorizations. Specifically, the existence of the passionate gamer who is also a non-frequent user counters assumptions that one must frequently engage in an activity to identify with it, which extends beyond just video 
gaming research. Moreover, in line with expectations surrounding problematic gaming, there was a greater effect size for differences between gamers and non-gamers compared to the effect size for the differences between frequent and non-frequent video game users, suggesting passionate engagement might play a more meaningful role in explaining increased problematic gaming. Future research is needed to address this finding more rigorously, however, as a simple comparison of effect sizes is not sufficient evidence in itself to support one dependent variable over another.

Finally, the present findings support the hypothesis that gamers and frequent video game users are more strongly motivated to play video games than non- gamers and non-frequent video game users, respectively. Of particular interest are the high effect sizes for differences between gamers and non-gamers for the motivations representing more autonomously motivated gaming. This is in line with perspectives of passionate engagement as a self-defining activity in an individual's life, suggesting it matches that individual's values and goals (Vallerand, 2010, 2015). Interestingly, the effect sizes for the differences between frequent and non-frequent video game users were small according to standards developed by Cohen (1988), whereas differences between socially identified gamers and non-gamers surpassed a large effect. Therefore, differences in motivation between gamers and non-gamers based on an individual's identification toward gaming could potentially be a more informative classification procedure rather than previously used measures of time spent playing or one item measures as used in previous research (Gordon, Juang, \& Syed, 2007; Kowert \& Oldmeadow, 2013; Neys et al., 2014). However, future research would be needed to compare these various measures. 
Overall, these findings have important methodological and practical implications for future research and clinicians to take into account. First, using the four items of the Vallerand's (2010) Passion Scale to classify participants in terms of their social identification as gamers and non-gamers in conjunction with an assessment of their frequency of gaming each week provides a much more detailed and objective approach at teasing apart the different types of video game players. Not only are the classifications much more specific for research purposes, but they are also more helpful in a practical context when examining behaviours related to each type of player and possibly which groups might be more at risk of developing Internet gaming disorder.

This study is limited in the following ways. First, data were collected through convenience sampling such as advertisements on social media sites and on a college campus, suggesting that this sample may not be representative. Moreover, this study relied on self- report data which, although convenient, assumes all participants interpreted each item correctly and responded truthfully. Finally, violations of equal variances within several of the present analyses does limit the interpretation of the corresponding effect sizes. However, these violations do not void the significant results given the robustness of the F test (Bird, 2004; Lindman, 1992). Notwithstanding these limitations, the present results add to the existing literature and future research by highlighting some of the more detailed differences between gamers and video game users.

The present study was unable to include gender as a third independent variable due to issues concerning cell sizes. Therefore, a primary recommendation for future research is the inclusion of gender as an independent variable to assess for possible 
interactions instead of controlling for gender differences. Finally, future research may want to focus on additional variables other than frequency and identification that further differentiate gamers and users. For instance, exploring the potential differences in the problematic patterns of engagement of each of the groups examined in the present study may help to further conceptualize and target specific needs of problematic gamers during treatment.

In conclusion, the present study is the first to demonstrate the validity of using the four-item subscale of the Passion Scale (Vallerand, 2010) in the classification of gamers versus non-gamers. Through the application of SDT, the definition of a socially identified gamer is suggested to include a perception that gaming is a meaningful and self-defining activity, which stems from a largely autonomous regulation of gaming engagement. Therefore, unlike non-passionate users who may play frequently, for passionate gamers video gaming aligns with their values and goals representing an element of their identity. 


\section{References}

American Psychiatric Association. (2013). Diagnostic and Statistical Manual of Mental

Disorders- Text Revision (5th ed.). Arlington, VA: American Psychiatric Association (APA).

Beard, C. L. \& Wickham, R. E. (2016). Gaming- contingent self-worth, gaming motivation, and Internet Gaming Disorder. Computers in Human Behaviour, 61, 507-515.

Bird, K. (2004). Analysis of variance via confidence intervals. Thousand Oaks: SAGE Publishing.

Brunborg, G. S., Mentzoni, R. A., \& Froyland, L. R. (2014). Is video gaming, or video game addiction, associated with depression, academic achievement, heavy episodic drinking, or conduct problems Journal of Behavioural Addictions, 3, 27-32.

Charlton, J. P. (2002). A factor-analytic investigation of computer 'addiction' and engagement. 
British Journal of Psychology, 93, 329-344.

Charlton, J. P., \& Danforth, I. D. W. (2007). Distinguishing addiction and high engagement in the context of online game playing. Computers in Human Behaviour, 23, 1531-1548.

Cohen, J. (1988). Statistical power analysis for the behavioural sciences (2nd ed.). Hillsdale: Routledge.

Deci, E. L., \& Ryan, R. M. (1985). The general causality orientations scale: Self-determination in personality. Journal of Research in Personality, 19, 109-134.

Deci, E. L., \& Ryan, R. M. (2000). The "what" and "why" of goal pursuits: Human needs and the self- determination of behaviour. Psychological Inquiry, 11, 227-268.

Fox, J., \& Tang, W. J. (2014). Sexism in online video games: The role of conformity to masculine norms and social dominance orientation. Computers in Human Behaviour, 33, $314-320$.

Fuster, H., Oberst, U., Griffiths, M., Carbonell, X., Chamarro, A., \& Talarn, A. (2012). Psychological motivation in online role-playing games: A study of Spanish World of Warcraft players. Annals of Psychology, 28, 274-280.

George, D., \& Mallery, P. (2010). SPSS for Windows step by step: A simple guide and reference 17.0 Update. (10th ed.), Boston: Pearson.

Gordon, C. F., Juang, L. P., \& Syed, M. (2007). Internet use and well-being among college students: Beyond frequency of use. Journal of College Student Development, 48, 674688. 
Johnson, D., Gardner, J., \& Sweetser, P. (2016). Motivations for videogame play: Predictors of time spent playing. Computers in Human Behaviour, 63, 805-812.

King, D. L., Delfabbro, P., \& Griffiths, M. (2009). The psychological study of video game players: Methodological challenges and practical advice. International Journal of Mental Health and Addiction, 7, 555- 562.

King, D. L., Haagsma, M. C., Delfabbro, P. H., Gradisar, M., \& Griffiths, M. D. (2013). Toward a consensus definition of pathological video-gaming: A systematic review of psychometric assessment tools. Clinical Psychology Review, 33, 331-342.

Kowert, R., \& Oldmeadow, J. A. (2013). Social reputation: Exploring the relationship between video game involvement and social competence. Computers in Human Behaviour, 29, $1872-1878$.

Lafrenière, M. K., Vallerand, R. J., Donahue, E. G., \& Lavigne, G. L. (2009). On the costs and benefits of gaming: The role of passion. Cyber Psychology and Behaviour, 12, 285-290.

Lafrenière, M. K., Verner-Filion, J., Vallerand, R. J. (2012). Development and validation of the Gaming Motivation Scale (GAMS). Personality and Individual Differences, 53, 827- 831.

Lemmens, J. S., Valkenburg, P. M., \& Peter, J. (2011). Psychosocial causes and consequences of pathological gaming. Computers in Human Behaviour, 27, 144-152.

Lemmens, J. S., Valkenburg, P. M., \& Gentile, D. A. (2015). The internet gaming disorder scale. Psychological Assessment, 27, 567-582. 
Lewsey, J. D., Gardiner, W., \& Gettinby, G. (1997). A study of simple unbalanced factorial designs that use type ii and type iii sums of squares. Communications in StatisticsSimulation and Computation, 26, 1315-1328.

Lindman, H. (1992). Analysis of variance in experimental designs. New York, NY: Springer.

Lucas, K., \& Sherry, J. L. (2004). Sex differences in video game play: A communication-based explanation. Communication Research, 31, 499-523.

Mageau, G. A., Vallerand, R. J., Charest, J., Salvy, S., Lacaille, N., Bouffard, T., \& Koestner, R. (2009). On the development of harmonious and obsessive passion: The role of autonomy support, activity specialization, and identification with the activity. Journal of Personality, 77, 601-646.

McLean, L., \& Griffiths, M. D. (2013). Female gamers: A thematic analysis of their gaming experience. International Journal of Game-Based Learning, 3, 54-71.

Müller, K. W., Janikian, M., Dreier, M., Wölfing, K., Beutel, M. E., Tzavara, C., Richardson, C., \& Tsitsika, A. (2015). Regular gaming behaviour and internet gaming disorder in European adolescents: Results from a cross-national representative survey of prevalence, predictors, and psychopathological correlates. European Child and Adolescent Psychiatry, 24, 565-574.

Neys, J. L. D., Jansz, J., \& Tan, E. S. H. (2014).

Exploring persistence in gaming: The role of self- determination and social identity. Computers in Human Behaviour, 37, 196-209. 
Padilla-Walker, L. M., Nelson, L. J., Carroll, J. S., \& Jensen, A. C. (2009). More than just a game: Video game and internet use during emerging adulthood. Journal of Youth and Adolescence, 39, 103-113.

Przybylski, A. K., Ryan, R. M., \& Rigby, C. S. (2010). A motivational model of video game engagement. Review of General Psychology, 14, 154- 166.

Przybylski, A. K., Weinstein, N., Ryan, R. M., \& Rigby, C. S. (2009). Having to versus wanting to play: Background and consequences of harmonious versus obsessive engagement in video games. Cyberspychology and Behaviour, 12, 485- 492.

Rehbein, F., Kliem, S., Baier, D., Möble, T., \& Petry,

N. M. (2015). Prevalence of internet gaming disorder in German adolescents: Diagnostic contribution of the nine DSM-5 criteria in a state- wide representative sample. Addiction, $110,842-851$.

Ryan, R. M. (1995). Psychological needs and the facilitation of integrative processes. Journal of Personality, 63, 397-427.

Ryan, R. M., \& Deci, E. L. (2000). Self- determination theory and the facilitation of intrinsic motivation, social development, and well-being. American Psychologist, 55, 68-78

Ryan, R. M., Rigby, C. S., \& Przybylski, A. (2006). The motivational pull of video games: A self- determination theory approach. Motivation and Emotion, 30, 344-360.

Shaw, A. (2012). Do you identify as a gamer? Gender, race, sexuality, and gamer identity. New Media \& Society, 14, 28-44. 
Tamborini, R., Bowman, N. D., Eden, E., Grizzard, M., \& Organ, A. (2010). Defining media enjoyment as the satisfaction of intrinsic needs. Journal of Communication, 60, 758- 777.

Utz, S., Jonas, K. J., Tonkens, E. (2012). Effects of passion for massively multiplayer online role- playing games on interpersonal relationships. Journal of Media Psychology, 24, 7786.

Vallerand, R. J., Blanchard, C., Mageau, G. A., Koestner, R., Ratelle, C., Léonard, M., Gagné, M., \& Marsolais, J. (2003). Les passions de l'âme: On obsessive and harmonious passion. Journal of Personality and Social Psychology, 85, 756-767.

Vallerand, R. (2010). On passion for life activities: The dualistic model of passion. Advances in Experimental Social Psychology, 42, 97-193.

Vallerand, R. (2015). The psychology of passion: A dualistic model. New York, NY: Oxford University Press.

Wei, H., Chen, M., Huang, P., \& Bai, Y. (2012). The association between online gaming, social phobia, and depression: An internet survey. BioMed Central Psychiatry, 12, 92-99.

Williams, D., Consalvo, M., Caplan, S., \& Yee, N. (2009). Looking for gender: Gender roles and behaviours among online gamers. Journal of Communication, 59, 700-725.

Winn, J. \& Heeter, C. (2009). Gaming, gender, and time: Who makes time to play? Sex Roles, $61,1-13$.

Yee, N. (2006). The demographics, motivations and derived experiences of users of massively multi- user online graphical environments. Presence, 15, 309-329. 
Tables and Figures 
Table 1

Crosstabulation of the Means and Standard Deviations of Gaming Engagement, Gaming Motivation, and Problematic Gaming across Gender

\begin{tabular}{|c|c|c|c|c|c|c|c|c|c|}
\hline \multirow{3}{*}{ Variable } & \multicolumn{6}{|c|}{ Gender differences } & & \multirow{2}{*}{\multicolumn{2}{|c|}{ Tatal asmola }} \\
\hline & \multicolumn{2}{|c|}{ Male } & \multicolumn{2}{|c|}{ Female } & \multicolumn{3}{|c|}{$t$-tests } & & \\
\hline & $M$ & $S D$ & $M$ & $S D$ & $t$ & $d f$ & $p$ & $M$ & $S D$ \\
\hline \multicolumn{10}{|l|}{ Gaming engagement } \\
\hline Free time play & 3.91 & 0.72 & 3.33 & 0.92 & 9.66 & 456.18 & $<.001$ & 3.74 & 0.83 \\
\hline $\begin{array}{l}\text { Hours of gaming } \\
\text { per week }\end{array}$ & 19.94 & 14.16 & 10.12 & 10.85 & 11.77 & 716.01 & $<.001$ & 16.97 & 13.99 \\
\hline Stress management & 2.37 & 0.71 & 2.20 & 0.76 & 3.45 & 971 & .001 & 2.32 & 0.73 \\
\hline \multicolumn{10}{|l|}{ Gaming motivation } \\
\hline Intrinsic & 4.39 & 1.20 & 3.88 & 1.42 & 5.38 & 482.38 & $<.001$ & 4.23 & 1.29 \\
\hline Integrated & 3.00 & 1.57 & 2.42 & 1.50 & 5.29 & 971 & $<.001$ & 2.82 & 1.57 \\
\hline Identified & 3.27 & 1.46 & 2.76 & 1.49 & 4.97 & 971 & $<.001$ & 3.12 & 1.49 \\
\hline Introjected & 1.82 & 0.98 & 1.66 & 1.00 & 2.35 & 971 & .02 & 1.77 & 0.99 \\
\hline Extrinsic & 3.47 & 1.48 & 3.03 & 1.55 & 4.28 & 971 & $<.001$ & 3.34 & 1.52 \\
\hline Amotivation & 1.81 & 1.14 & 1.72 & 1.05 & 1.20 & 971 & .23 & 1.78 & 1.11 \\
\hline \multicolumn{10}{|l|}{ Problematic gaming } \\
\hline Gaming disorder & 2.15 & 0.80 & 1.96 & 0.82 & 3.27 & 971 & .001 & 2.09 & 0.81 \\
\hline
\end{tabular}

Table 2

Crosstabulation of Gamer Classification and Frequency of Video Game Usage Across Genders

\begin{tabular}{|c|c|c|c|}
\hline \multirow{3}{*}{ Variable } & \multicolumn{2}{|c|}{ Gender } & \multirow{3}{*}{$\begin{array}{l}\text { Total } \\
n(\%)\end{array}$} \\
\hline & Men & Women & \\
\hline & $n(\%)$ & $n(\%)$ & \\
\hline \multicolumn{4}{|l|}{ Gamer classification } \\
\hline Gamer & $521(76.73)$ & $149(50.68)$ & $670(68.86)$ \\
\hline Non-gamer & $158(23.27)$ & $145(49.32)$ & $303(31.14)$ \\
\hline \multicolumn{4}{|l|}{ Frequency of use } \\
\hline Frequent user & $626(92.19)$ & $217(73.81)$ & $843(86.64)$ \\
\hline Non-frequent user & $53(7.81)$ & $77(26.19)$ & $130(13.36)$ \\
\hline
\end{tabular}

Table 3

Univariate Tests and Effect Sizes for Gamer Classification

\begin{tabular}{|c|c|c|c|c|c|c|c|}
\hline \multirow{2}{*}{ Variables } & \multicolumn{2}{|c|}{ Gamer } & \multicolumn{2}{|c|}{ Non-gamer } & \multicolumn{3}{|c|}{ Univariate tests and effect sizes } \\
\hline & $M$ & & & & & & $p$ \\
\hline \multicolumn{8}{|l|}{ Gaming engagement } \\
\hline Free time play & 4.07 & 0.58 & 3.01 & 0.85 & $153.32^{\mathrm{a}}$ & $<.001$ & .14 \\
\hline Hours per week gaming & 21.51 & 14.01 & 6.93 & 6.90 & $28.57^{\mathrm{a}}$ & $<.001$ & .03 \\
\hline Stress management & 2.50 & 0.69 & 1.91 & 0.66 & $51.45^{\mathrm{a}}$ & $<.001$ & .05 \\
\hline \multicolumn{8}{|l|}{ Gaming motivation } \\
\hline Intrinsic & 4.67 & 1.04 & 3.25 & 1.26 & $220.67^{b}$ & $<.001$ & .19 \\
\hline Integrated & 3.43 & 1.49 & 1.49 & 0.64 & $347.56^{\mathrm{c}}$ & $<.001$ & .26 \\
\hline Identified & 3.67 & 1.37 & 1.90 & 0.90 & $312.60^{\mathrm{c}}$ & $<.001$ & .24 \\
\hline Introjected & 2.00 & 1.07 & 1.26 & 0.46 & $92.69^{c}$ & $<.001$ & .09 \\
\hline Extrinsic & 3.73 & 1.45 & 2.48 & 1.28 & $96.81^{\mathrm{c}}$ & $<.001$ & .09 \\
\hline Amotivation & 1.78 & 1.13 & 1.78 & 1.07 & $0.69^{c}$ & .41 & - \\
\hline \multicolumn{8}{|l|}{ Problematic gaming } \\
\hline Gaming disorder & 2.29 & 0.81 & 1.65 & 0.61 & $93.65^{d}$ & $<.001$ & .09 \\
\hline
\end{tabular}

Note. ${ }^{a} F(3,968),{ }^{b} F(1,971),{ }^{c} F(1,972),{ }^{d} F(1,968)$. 
Table 4

Univariate Tests and Effect Sizes for Frequency of Use

\begin{tabular}{|c|c|c|c|c|c|c|c|}
\hline \multirow{2}{*}{ Variables } & \multicolumn{2}{|c|}{ Gamer } & \multicolumn{2}{|c|}{ Non-gamer } & \multicolumn{3}{|c|}{ Univariate tests and effect sizes } \\
\hline & $\mathrm{AT}$ & n & $A A$ & sh & $F$ & $n$ & $n^{2}$ \\
\hline \multicolumn{8}{|l|}{ Gaming engagement } \\
\hline Free time play & 3.92 & 0.65 & 2.53 & 0.87 & $165.99^{\mathrm{a}}$ & $<.001$ & .15 \\
\hline Hours per week gaming & 19.16 & 13.73 & 2.80 & 3.07 & $67.47^{\mathrm{a}}$ & $<.001$ & .07 \\
\hline Stress management & 2.40 & 0.71 & 1.77 & 0.64 & $20.58^{a}$ & $<.001$ & .02 \\
\hline \multicolumn{8}{|l|}{ Gaming motivation } \\
\hline Intrinsic & 4.39 & 1.20 & 3.20 & 1.39 & $17.82^{\mathrm{b}}$ & $<.001$ & .02 \\
\hline Integrated & 3.00 & 1.57 & 1.67 & 0.99 & $6.24^{\mathrm{b}}$ & .01 & .01 \\
\hline Identified & 3.28 & 1.47 & 2.06 & 1.13 & $6.32^{\mathrm{b}}$ & .01 & .01 \\
\hline Introjected & 1.85 & 1.02 & 1.26 & 0.55 & $6.62^{b}$ & .01 & .01 \\
\hline Extrinsic & 3.51 & 1.48 & 2.26 & 1.29 & $21.47^{\mathrm{b}}$ & $<.001$ & .02 \\
\hline Amotivation & 1.81 & 1.13 & 1.61 & 0.95 & $0.78^{b}$ & .38 & - \\
\hline \multicolumn{8}{|l|}{ Problematic gaming } \\
\hline Gaming disorder & 2.18 & 0.81 & 1.55 & 0.58 & $18.92^{\mathrm{c}}$ & $<.001$ & .02 \\
\hline
\end{tabular}

Note. ${ }^{\mathrm{a}} F(3,968),{ }^{b} F(1,972),{ }^{c} F(1,968)$. 
a)

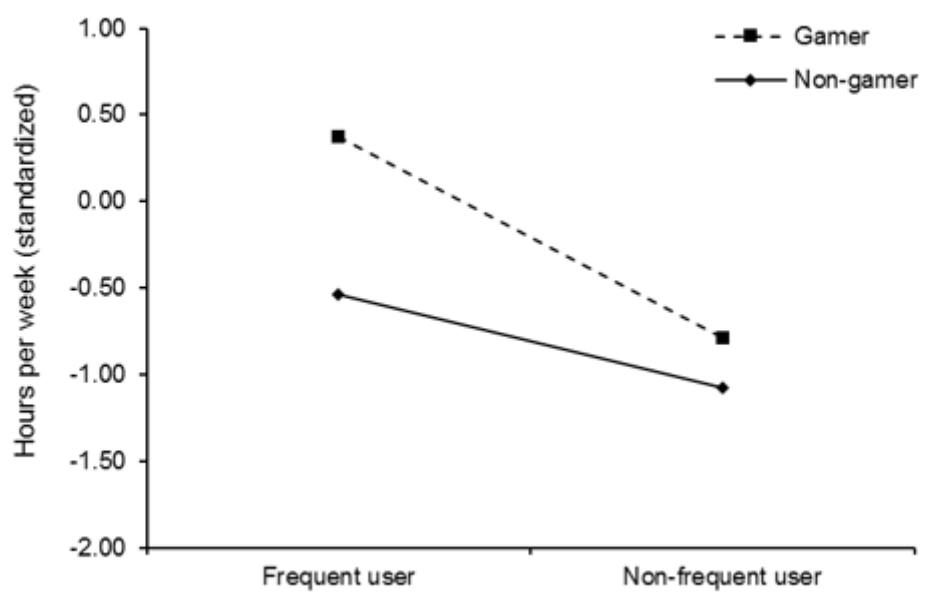

b)

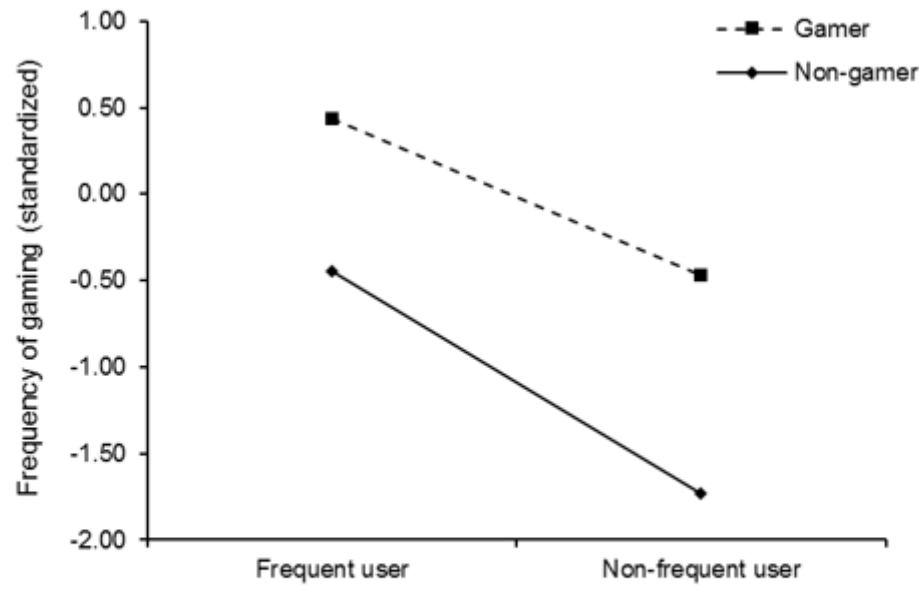

Figure 1. Interactions for hours per week gaming (A) and frequency gaming in free time (B). 